\section{E-LOGOS}

ELECTRONIC JOURNAL FOR PHILOSOPHY ISSN 1211-0442

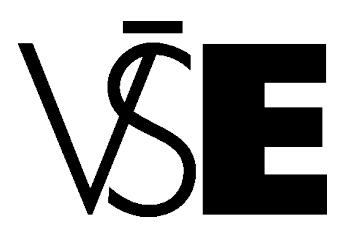

University of Economics

Prague

\title{
Introducing Husserl's
}

Phenomenology from an Aristotelian

Point of View

Khalid Jamil Rawat

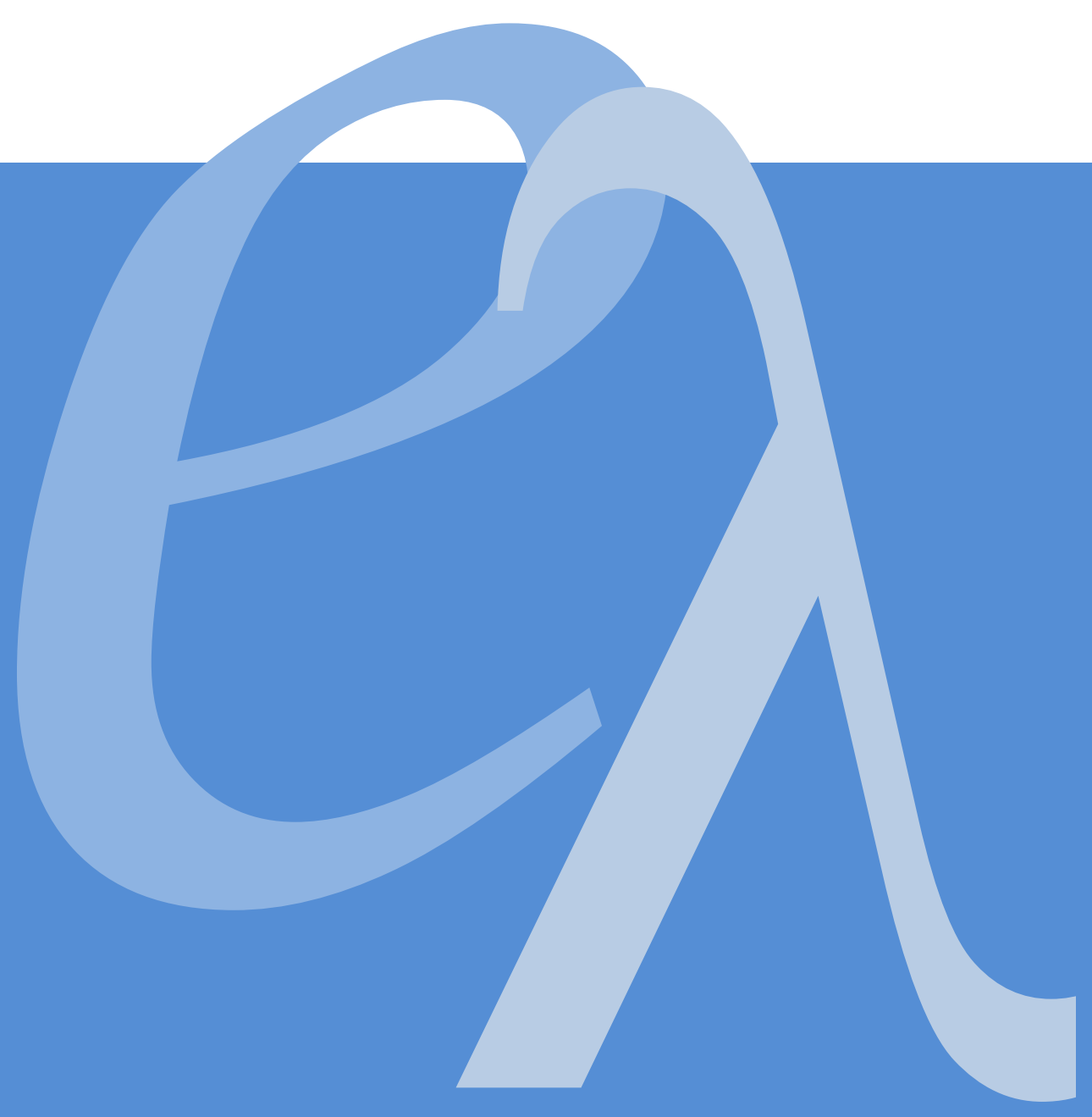




\begin{abstract}
Although, phenomenological method in its spirit and assumptions is entirely different from Aristotelian method, the need to juxtapose these philosophies is justified on the ground that the two should be properly differentiated from each other, and their differences and similarities should be brought to light. For at times the homonymy of the terms used in two methods creates a conceptual error in the mind. These terms include among other knowledge. The article gives a brief overview of Husserl's phenomenology and its parallels in Aristotle's philosophy.
\end{abstract}

Keywords: Aristotle, Husserl, phenomenology. 
According to Husserl, phenomenology is different from natural science methods and natural attitude towards understanding because its focus is different; rather than focusing on the world of nature, or events in nature, phenomenology studies the lived experience of the ego that experiences the world. In phenomenological investigations any assertion or belief about the natural world is suspended, and pure consciousness, to which things in nature appear as phenomenon, is accessed through reflection. Phenomenology is not the study of nature; it is the study of spirit or mind that experiences nature or itself.

Aristotle, in his works like De Anima, Metaphysics, Topics, Categories and Prior and Posterior Analytics has explicitly discussed the way human consciousness becomes aware of something. Aristotle discussed the issue of human consciousness while focusing on notions like substance, essence, accident, property, form, categories of Being, causes, active and passive intellect and sense perception. However, it is arguable that whether or not the basic concern of phenomenology is kept intact in his discussion.

The most fundamental concern of phenomenology, according to Husserl is to develop a science and a method that can study the pure consciousness. Pure consciousness is achieved when one abstracts from human experiences, in a systematic and methodic manner, all elements of the natural world. Phenomenology basically is the study of the spiritual, or the 'lived experiences' of the ego that undergoes experiences and it does not focus the object of experience. In natural attitude one studies and remains preoccupied with the object of experience; in phenomenology one studies the way this object is given or presented to the consciousness.

For Aristotle on the other hand, as depicted in his writings, knowledge basically means to know the causes and principles that can explain the existence of something. These include, for instance as depicted in his Posterior Analytics, the existence of a connection between an attribute and a substance, the cause for the connection between an attribute and a substance, the existence of a particular thing , and the cause for its existence.

In his metaphysics, where Aristotle takes an investigation of being as his theme, he called knowledge the knowledge of first principles and causes. As far as method is concerned, Aristotle adopted the method of dialectics in his inquiry into being in metaphysics. In posterior analytics the nature of scientific knowledge is discussed .In prior analytics he deals with the formal aspect of the method of deduction and the quality of proofs and propositions that one uses to express his knowledge of something. The point is, for Aristotle, it is not the quality of method, as we think today, in terms of its validity and reliability that makes knowledge valuable; rather it is the quality of proposition and their power to demonstrate and explain something that is important. So, for Aristotle knowledge in general does not rely on any kind of specific 
method; it merely relies on how successfully a set of propositions is capable of explaining the existence of something 1 .On the other hand, for Husserl method is of great significance, and he wants to develop his method of phenomenology as a method with rigor and clarity of modern day scientific methods.

Husserl adopts a method that analyzes the structures of consciousness. Since, human consciousness works only in the context of the natural world; its experiences are always already of the world (borrowing Heidegger's term). This, in Husserl's terminology means that human experience is founded in the natural world, so the data for phenomenology comes from the experiences carried out in the natural world. Applying the method of phenomenology on this data, one reaches, through reflecting upon the experiences, the purely spiritual. Owing to the habits of understanding developed in the natural world, one finds it difficult to understand that phenomenology does not rely on these habits. Phenomenology, on the other hand, asks one to bracket or suspend any pre existing judgments about the natural world. However, the situation becomes more difficult to handle when the same linguistic signs are equivocally used. Husserl gives the example of the term analysis. He writes:

“... every genuine material analogy between analysis of consciousness and analysis of nature, whether physical, chemical, or even biological, falls away, as does the whole analogy between the way of being of consciousness and the ' $\mathrm{I}$ ' of consciousness, (on the one hand)and on the other hand, the way of being of nature. The concepts of physical thing and attributes, of whole and part, uniting and separating, cause and effect, and the like, which are logical when applied to Nature, are all of them rooted in the originarily real, that is, in Nature, and therewith in its basic determination, res extensa. When they are taken over into the realm of the mental, i.e., as psycho-logical, these concepts lose what is fundamentally essential to their meaning, and what remain are only the empty husks of formal-logical concepts of object, attribute, composition, and so on." 2

Husserl has also described phenomenology as the science of pure phenomenon ${ }^{3}$. Phenomenon means appearance; objects rather than being fully given to our consciousness appear through phenomenon of consciousness .Furthermore, these phenomena are given to our consciousness through different modes like desiring, expectation, perception, remembering etc. We perceive things through looking at them, we can imagine them, we can experience them as objects of different mental acts like desiring, expectation, judgment etc.

\footnotetext{
${ }^{1}$ Witt, Ch., Substance and Essence in Aristotle: An Interpretation of Metaphysics xii-ix; Cornell University Press 1989, pg. 10-18.

${ }^{2}$ Husserl, E., Amsterdam Lectures, tr. by: R.E Palmer : available online: http://www.stanford.edu/dept/relstud/faculty/sheehan.bak/EHtrans/z-amster.pdf

${ }^{3}$ Husserl, E. Pure Phenomenology, its Method and its Field of Investigation, tr. by: Robert Welsh Jordan ; available online: http://lamar.colostate.edu/ rwjordan/W-INAUGFRB.HTML
} 
This position taken by Husserl can be compared with Aristotle's position on equivocality in Categories, in which he says that there is a possibility that two things share name but not the definition. Aristotle gives the example of an animal on foot and an animal in a picture. In both cases it is the animal, but the way of being in the picture is different from the way of being of animal on foot. In the same book he writes about primary substances that they can acquire contradictory qualities without losing their identity. In these examples it is clear that primary substances do not lose their identity, even if their way of being is changed. Thus primary substances, without losing their identity appear before the perceiver, and they are capable of appearing in various manners. For instance, a man who was bad in manners and attributed with this evil quality, after some kind of moral practice becomes good, and now he is attributed with good qualities. The personality of this man undergoes changes, yet the same person who was once bad, now becomes good, thus retains his identity ${ }^{4}$. This identity for Aristotle is what he calls the identity of name. A name cannot be both said of and not said of the same thing, for according to the law of non contradiction, A cannot be both A and non-A. Thus, a substance can only have one name.

So, according to Aristotle, a similar substance, notwithstanding its changing ways of being, retains its identity, and can exist in different modalities. These various ways of appearing in Aristotle can be equated to Husserl's notion of phenomenon.

The example of an animal on foot and an animal in picture can be extended to an animal in imagination, in dream, as an object of will, desire, fear etc,. In each of these examples the primary substance does not lose its identity, yet its ways of being differed. Furthermore, Aristotle very strictly maintains that by identity he means that the same thing, nominated by a name, cannot differ from itself. Thus Aristotle's notion of substance with its various ways of being resemble Husserl's notion of phenomenon.

According to Husserl there are innumerable ways in which we become aware of or conscious of something and these modes are connected to their object through what Husserl calls intentionality. Intentionality, being bipolar, has at one end the act through which one knows and on the other the object thus known. The act part is called noesis by Husserl and the object of which the phenomenon is given, is called noema.

Intentionality, thus, is the essential property of consciousness, and assures that our consciousness is always 'of' or 'about' something. Consciousness remains a mere potential until it identifies something as something, and thus becomes the consciousness of that something. Consciousness does not become consciousness before it objectivates something; it always has an object, a 'this' or a 'that'.

4 Aristotle, Categories, Book 1, tr. By: E.M Edghill, Internet Classic Archive: Available Online: http://classics.mit.edu/Aristotle/categories.html (last retrieved 05-04-2011) 
Suppose, if I recognize a certain Mr. A as Mr. A, then this amounts to recognizing my object of consciousness as both a primary and a secondary substance. So the answer to the question, what my consciousness has objectivated when I perceived or remembered Mr. A, can be given in terms of both primary and secondary substances. The answer can be, 'a man' and also Mr. A. For Aristotle the essence of Mr. A is his being a man, a universal. Husserl on the other hand does not treat essence this way, and for him the essence means that which remains invariable in infinite manifestations of the object. So, the form, 'man' which is the essential for Aristotle in the case of a particular man, remains merely a part of the essence of a particular Mr. A. But it is not guaranteed that in the end Husserl comes up with something new added to this essence, yet we can hope that phenomenological description can enrich the meaning of this essence. So, may be the essence, that which remains invariable in infinite manifestations of Mr. A remains his being a man, yet Husserl's description may increase the number of differentia in the various definitions of man.

So the difference between Aristotle and Husserl may not lie in the recognition of man as the essence of a particular Mr. A , but in what a man is. What this form 'man' is? And to re-describe this form, this age old essence, Husserl wants to look back towards the things and objects, to see what actually there meaning is.

So, the description of essence as that which remains invariable in infinite variations or manifestations of an object is strengthened by Husserl's dictum of 'going back to the things themselves.' The significance of this going lies in the fact that the linguistic sign, to which we have attached an ideality, an ideal object, an interpretation of the object's phenomenoa by our minds, the very schema that we draw of an object, is to be forsaken, and in its lieu a liberated awareness of the thing in itself is to be brought forward. That traditional ideality is to be bracketed through the exercise of epoche' or phenomenological reduction. So the fire I always see as a habit, is not the object in itself but an already established conventional ideality that is to be bracketed in favor of a radical viewing of an object, in which object is to be seen as it is given to my consciousness. Phenomenology asks for a reconstruction of an object of consciousness, and for a break up with the traditional ways of objectivating.

Aristotle's discussion on substance and various essences, being a part of tradition, appears to be something that should be changed. These definitions must have a radically new meaning, and must have exemplified a new way of looking at things in the times of Aristotle, but now these are only traditional ways needing a change; they only form a part of an old convention. Husserl on the other hand is more interested in criticizing the convention and asks for a break up with traditional idealities, the metaphors of perception.

Consciousness is the recognition of something as something. So, Whenever we are 'conscious' or 'aware'..., we are actually conscious or aware 'of 'something as 
something; if we are aware of a 'tree', through imagining it, the object of our consciousness is that tree, and has an intentional inexistence in our consciousness. This notion of intentional inexistence liberates us from the problem of existence dependence such that we can think about something that does not exist. We can think about a unicorn without bothering us about its existence, thus making this thought of unicorn a phenomenon of consciousness; a phenomenon that can be studied. Intentional inexistence allows one to study how different objects are given to consciousness; objects like God, angels, beliefs, etc., about which one cannot hypothesize whether they exist or not.

Intentionality has a special significance in Aristotle's philosophy; it appears as a bridge between object and its awareness .In order to grasp the full meaning of consciousness and intentionality, we will have to address the question of knowledge in its basic form from an Aristotelian point of view.

\section{Two Types of Beings}

If we have a look at ourselves and our surroundings, we will see that there are two types of beings present in the world. There are those who have both self awareness and the awareness of the others, and those who neither have self knowledge nor the knowledge of others. Every living being belongs to the first category and these first category beings are called the 'Sentient Beings'. The second category that includes all the non-living objects is the category of non-sentient beings.

A chair, a car, a table and a bus are examples of non-sentient beings. Non sentient beings are not aware of anything, so whether or not others exist for them, is uncertain. Similarly, since they are not aware of anything; therefore they also don't exist for themselves. On the other hand, sentient beings are beings for themselves because they have self awareness. Now let us think about the way a sentient being knows itself or other beings. Aristotle has to make many important points about this issue.

Awareness of things comes through senses, such that, when our sense of sight receives an image we see that image ${ }^{5}$. Now the question is whether the things we see through our eyes have existence apart from their images that we see? For example if there is no one to see this world, means no being with the sense of sight survives in the world, then, will the world still keep its visual appearance. Since our senses mediate between the objects we perceive and our perception of the objects, therefore, it can be said that our senses represent things to us and it is a mere representation that we see and not the reality of which it is a representation. Thus, our eye is an organ or a sense that represents this world in a visual form. If eyes don't survive in this world the visual representation will no longer be there. Similarly what we hear in this world

${ }^{5}$ Aristotle, De Anima, Internet Classic Archive, Available Online: http://classics.mit.edu/Aristotle/soul.html 
is not the reality, but representation of reality in an audible form. Hence, if there remain no ears in this world, the audible representation will also vanish. In a similar fashion, we can say that if senses disappear from this world nothing will exist. This gives us the idea that things that we know are mere representations of some unknown reality which may or may not exist.

If we observe a chair, we actually observe the way this chair is represented by our senses to our consciousness, and the thing, the reality, of which this chair is the representation, is not given to us. This non-given reality is termed by Kant, the-thingin-itself. However, there is doubt that whether or not this thing-in-itself exists. Now, there are some possible answers to this question.

1. The Aristotelian Reply

2. The Kantian and

3. The Husserlian Reply

According to Aristotle there is a primary matter that is a mere possibility and all properties of things actually reside in this matter6. These properties include form, shape, colors, size etc. Aristotle believes in matter and accepts the existence of an external reality. This faith in the existence of matter, allows him to affirm the existence of the things in the world outside, independent of the observer.

For Aristotle senses are potentialities like matter, and they assume the qualities of the object perceived through them. The eye becomes what it perceives; the ear becomes what it listens to; but the only difference is that the visual and auditory forms are divested of matter, for eye and ear become the substrate for these forms ${ }^{7}$. The presence of this form divested of matter is also termed as intentional inexistence, and is a precursor of the modern concept of intentionality. For example, a unicorn does not exist, yet it has an intentional inexistence in one's consciousness. So, if one is conscious of something, like a unicorn, even if that thing does not exist, it has an intentional inexistence.

For Aristotle, the number of causes that enable a thing to exist can be reduced to four (material, formal, efficient and final). Things, in Aristotle's philosophy, are said to have both essential and accidental qualities. Essential qualities are those whose separation from the thing changes the definition of the thing, where as the separation of an accidental quality does not change its definition. Thus, for Aristotle whenever matter is allowed to adopt a form by an efficient cause to serve a purpose it becomes a

6 Aristotle, Metaphysics, tr. by: W. D. Ross, Internet Classic Archive: Available Online: http://classics.mit.edu/Aristotle/metaphysics.html

${ }^{7}$ Aristotle, De Anima. 
substance with or without accidental properties. Accidental qualities can be of varied nature and can be separated from the thing without affecting its essence.

In Topics Aristotle identified that four things can be said of a thing in a proposition. These include definition, Genus, Property and Accident ${ }^{8}$. Out of these four, definition gives the essence of a thing. However, these definitions are formulated only in universal terms; thus, one can identify a particular dog as a dog, or an animal, but somehow cannot know the primary substance, the particular horse.

Even if somebody knows a property, or an accident of the primary substance, the definition of these are also bound to be expressed in terms of universals. So, in a white dog, the whiteness cannot be known in its particularity; it will always remain a universal, whenever it is defined; and knowledge basically is to know the definition.

In Metaphysics, Aristotle defined form or the formal cause as equivalent to essence ${ }^{9}$.

In his Categories, Aristotle defines primary substance as the substrate for the secondary substances and other predicates. Sense organs convey the sensation of the primary substance, i.e., the individual or particular thing given to the senses with all its predicates. However, as far as predication is concerned, only universals are predicable to a subject. So, if one asks about the definition of a particular horse, the definition can only be given in terms of either the specie to which the particular horse belongs, the specie horse, or the genus, the animal. However, for him specie is more close to the primary substance, the particular thing, than genus. Hence, to say that 'this is a dog', is closer to the description of a particular dog than to say that' it is an animal.'

The essence of a thing, one can conclude, is the 'form.' This form, however, is different from the form that senses receive. This form, as Aristotle has depicted in De Anima is the form of the forms, and that mind or the active intellect discerns only the universal, the secondary substance. So the answer to the question, 'what is this', is always given in terms of secondary substances, or as the form of the forms, genus or specie.

For Aristotle, sense organs imitate the visual or auditory form and intellect displays the meaning of the perceived object, through giving it an intelligible form. The whole process of being conscious of something goes in this manner; sense organs become what they perceive, intellect gives meaning to the perception, through the essential features of the object yielding definitive understanding of an object in terms of secondary substances. Intellect tells us about the 'whatness' of an object; it tells us what an object is in terms of its essence and not in the terms of its particular existence. The

8 Aristotle, Topics, tr. by: W. A. Pickard-Cambridge, Internet Classic Archive: Available Online: http://classics.mit.edu/Aristotle/metaphysics.html

${ }^{9}$ Aristotle, Metaphysics. 
question, what an object is, yields essence, which is intelligible and universal, means that what an object is does not depend upon the mode of existence of that thing, rather it is something intelligible; an ideality in Husserl's words.

So, for both Aristotle and Husserl, the existing form, or the particular form, in Husserl's words a particular phenomenon of an object, in Aristotle's words the perception of primary substance through senses, does not include the essence, or the form of the forms, however, it is necessary for the understanding or intelligibility of the primary substance. That this essence or the form of the form truly is an ideality, never given to the senses, yet, without its understanding the particular cannot be comprehended as such. However as to what this ideality should be, Husserl wants to differ from Aristotle, for Aristotle is a part of convention.

According to Kant the thing-in-itself can never be known. We can never have an intuition of a thing in which the element of representation is not involved. Things are always represented, and pure intuition of a thing is not possible. The knowledge of the- thing-in-itself is not possible. However, Kant believes that there is a thing in itself out there and our faculties represent it to us.

According to Husserl, within phenomenological discipline, we can never say that things exist or not, thus whatever we are aware of is a phenomenon. Husserl writes:

“...Objects and phenomena stand in contrast with each other. Objects [Objekte], all natural Objects, for example, are objects foreign to consciousness. Consciousness does, indeed, objectivate them and posit them as actual, yet the consciousness that experiences them and takes cognizance of them is so singularly astonishing that it bestows upon its own phenomena the sense of being appearances of Objects foreign to consciousness...10"

So, for Husserl natural objects without any exclusion, are all foreign to consciousness, and consciousness, though it objectivates and posits these objects, presents the phenomenon of these objects as mere representations. It is here that Husserl's commitment to break the traditional idealities come to fore. Natural objects are not given to our consciousness; they are foreign to our consciousness, yet we call consciousness an actual consciousness when it is of something, of an object, an ideality should be present to make us conscious. And then it appears to be a contradiction here, for in the method of phenomenology one suspends belief in a transcendental ideality, the substance that remains invariable, and just tries to analyze what is given to the consciousness. So, in the use of method something that is given as something is not to be recognized as something. The fire I am looking at, is not the ideality, the transcendental object foreign to the consciousness, but only a phenomenon, and I have to suspend my judgment that recognizes it as fire, to see what actually is given to me.

${ }^{10}$ Husserl, E., Phenomenology, Its Method and Field of Investigation. 
And in the end I have to see what was that that remained invariable in all the observed instances of that phenomenon, to reconstruct an ideality, the fire again. But in its reconstruction, this ideality will surely add something new to its description. So, the end product of the method is the essence, the ideality, and is not a mere description of various instances of phenomenon.

Husserl accepts Cartesian cogito's "I think" part, but does not accept the conclusion that there is a world existing outside the ego. Husserl writes:

"The so-called phenomenological reduction can be effected by modifying Descartes' method, by carrying it through purely and consequentially while disregarding all Cartesian aims; phenomenological reduction is the method for effecting radical purification of the phenomenological field of consciousness from all obtrusions from Objective actualities and for keeping it pure of them."

Thus bracketing the belief in the existence of the world, Husserl differs both from Aristotle and Kant, who think that there is a reality of which the representations we know. Rather than assuming that there is a world outside, he thinks that the one who is bracketing the existence, the ego, should be studied qua its experiences. He does not accept the idea that God is there to broker the relationship between the world and the mind in a Cartesian sense, or that there is matter that certainly bestows existence to the things we are aware of. For Husserl the starting point is that the ego is aware of or conscious of something and the task that can be pursued after realizing this state of affair is to carry out the analysis of this consciousness ${ }^{11}$.

To perform this analysis, the methods employed by Husserl resemble the method of analysis developed by Aristotle in his Categories ${ }^{12}$ that separates accidental and essential properties. However, the difference between the two methods primarily lies in the fact that Husserl also separates or abstracts the contents of the natural world or nature from the contents of consciousness.

Husserl is interested in finding the essence of the way some thing is presented to consciousness. Husserl also utilizes Aristotelian notions of possible and actual frequently, though in a sense different from that of Aristotle. For Husserl, phenomenology is not the science of actual; instead it is the science of the possible $\mathrm{e}^{13}$. Husserl's interest in developing phenomenology as a science of possibilities is rooted in relating the finite ego with the infinite. Actualities are limited, yet still they are signposts towards the infinite possibilities. Phenomenological investigation starts with actual instances of experiences, yet it goes beyond these few actual instances, through increasing the horizon of possibilities with the help of imaginative variation, and also

\footnotetext{
${ }^{11}$ Husserl, E., Phenomenology, Its Method and Field of Investigation.

12 Aristotle, Categories, Book 1.

${ }^{13}$ Husserl, E., Phenomenology, Its Method and Field of Investigation.
} 
limiting this infinity through depicting the essence; the element that remains self same in all possible variations.

Husserl's interest is in knowing the possible forms that consciousness can take, i.e., the essence of the different possible modes of pure consciousness along with the pure laws. Husserl writes:

"Just as pure geometry is bound to shapes observed in actual experience but instead inquires into possible shapes and their possible transformations, constructing ad libitum in pure geometric phantasy, and establishes their essential laws, in precisely the same way pure phenomenology proposes to investigate the realm of pure consciousness and its phenomena not as de facto exists but as pure possibilities with their pure laws. ${ }^{\prime \prime \prime}$

In an act of consciousness all the predicates of the experience of an object, for consciousness essentially is of something, reside. Thus, if we want to know about the way we are aware of an object, we have to know the act of consciousness in which the thing or object is given to us. Like prime matter, our consciousness is a possibility which can take on any form. So, when we see a particular object our perception or sight presents that thing to our consciousness. And if we want to grasp the essence of such an experience, we have to employ the method of phenomenology.

The essence, in the likeness of the essence of a thing in Aristotelian sense, can be considered as the form of forms. Means, that if somebody is interested in knowing about the way a house is given to the perception, he has to take into account different experiences of perceiving the house(individual forms of experience), from which the universal form of this experience can be known, through fantasizing. This point is cited by Husserl 15 .Thus, we have to perform an analysis of the acts of consciousness and this method of phenomenological analysis is described by Husserl in detail.

\section{Husserl's Method of Phenomenology}

For Aristotle the question of knowing something is apparently simple. For Aristotle, knowledge is the knowledge of universals, for only universals are predicable to any subject. And these universals are well known in most of the cases, though Aristotle devoted part of his Posterior Analytics to inquire into the being of a thing in an unqualified manner. By unqualified manner he means to ask a question about the whole being of a thing and not about some particular aspect. So, according to Aristotle, if somebody asks, what is the Moon? He is asking a question about the being of the moon in the fullest sense. And for Aristotle, this answer can be given in a syllogistic form, and he has described the properties of this syllogism in detail. Yet he has not given any idea of how this knowledge can be achieved; how the premises can be

\footnotetext{
${ }^{14}$ Husserl, E., Phenomenology, Its Method and Field of Investigation.

${ }^{15}$ Husserl, E., Phenomenology, Its Method and Field of Investigation.
} 
constructed on which the conclusion is to be based. Aristotle's way is like that of an evaluator, who evaluates and tests the quality of finished product, without looking at the process involved in manufacturing that product.

Husserl however is also interested in the process and suggests a full method. The method is aimed at constructing essences. Husserl's notion of essence is complex and needs clarification, for rather than being the essence of a thing the essence under review is of the act of consciousness.

When we are aware of an object and our consciousness presents it to us, it is only an instance of the appearance of that object. In the act of consciousness, that is when consciousness actualizes itself through intending an object, two things happen. First, this can be described only as an instance of being conscious of an object, means, one can be aware of the same object through different other intentional acts. Second, it establishes the fact that the object given in one particular act remains same in all other acts in which it is intended. So an object intended in one act of consciousness can possibly be intended through various other possible acts of consciousness, without changing its identity. The chair which is the object of my consciousness right now can be intended through other dimensions not only by me alone but also by others at various instants, through various dimensions. The present instance of the actualization of my consciousness through intending this particular chair is a member of a set of all possible appearances of that object. The object however will remain same.

Husserl differentiates between two senses of experiencing and correspondingly the objects of these contrasting sorts, he writes:

"... of these contrasted sciences there correspond two fundamentally different types of experience and of intuition generally: immanent experience and Objective experience, also called "external" or transcendent experience. Immanent experience consists in the mere viewing that takes place in reflection by which consciousness and that of which there is consciousness are grasped. .6" $^{\prime \prime}$

On the other hand transcendental experience is actually referred to the experience carried out in a natural attitude, in which one posits an external world or object which is not immanent in the consciousness. One while in a natural attitude is preoccupied with the object perceived; the object on the other hand, is foreign to consciousness, thus transcendental.

The object of knowledge for Husserl is not this transcendental, external object; instead it is the universal form of the acts of consciousness that represent the object to the consciousness. Husserl writes:

${ }^{16}$ Husserl, E., Phenomenology, Its Method and Field of Investigation. 
"A person in the natural attitude, whoever ... executes the acts of experiencing, referring, combining; but, while he is executing them, he is looking not toward them but rather in the direction of the objects he is conscious of. ${ }^{17 "}$

This object of knowledge is not fully given in the instances, for one cannot study all possible instances of an experience. Thus, the object of study, the form of experience, is to be constructed through fantasizing or what Husserl calls free imaginative variation. For instance, let us consider the example of the act of perceiving a tree. When we see a tree from a certain angle, in one act of consciousness, we can logically infer that only a part of the tree is visible to us. Moreover, we can also legitimately think that there are several such perceptive acts are possible in which same tree is given. A particular act of perception does not represent the whole set of possible perceptive acts. Thus, in order to know the possible form of perception of a tree, one has to repeat this experience in one's imagination, to see what remains unchanged in changing perspectives. This invariant part of the experience that remains unchanged in each variation, establishes itself as the essence or form of this particular sort of experience. This in Husserl's terms amounts to know the full horizon of possibilities linked to a type of act of consciousness. In knowing the full horizon of possibilities, one also knows the present, past and future possibilities of an experience.

\section{Conclusion}

People like Robert Sokolowski consider Husserl's phenomenology as a study of intellect focusing intellect as its theme which is similar to Aristotle's focus in his Metaphysics. Sokolowski writes:

"Philosophy goes beyond physics because logic, truth...and the grasp of definitions are not among the motions, kineseis that occur in simply material entities. They are beyond the physical, meta ta physica. They belong to being as being, ...so when Aristotle turns to the examination of being as being, he also turns to the study of intellect as intellect, mind as mind, or reason as reason. This is also what Husserl does. We could define his phenomenology as the study of intellect as intellect, mind as mind, reason as reason."

So there is a great similarity between Husserl and Aristotle, both are studying intellect as intellect and being as being. However there are certain differences as well. Husserl is different from Aristotle in his commitment to method, though he also considers the apodictic nature of propositions as a quality that should be present in them to make them worthwhile from the perspective of knowing. Aristotle on the other hand is not that much concerned with the method and appreciates the demonstration power of propositions.

${ }^{17}$ Husserl, E., Phenomenology, Its Method and Field of Investigation. 
As far as knowledge is concerned both Aristotle and Husserl consider essences as the objects of knowledge. In both Aristotle and Husserl the possibility of constructing new essences is accepted. However Husserl gives a method for the construction of essences and idealities, whereas Aristotle does not suggest a method. Husserl has developed phenomenology as a science of spirit, whereas Aristotle talks about both matter and spirit.

However, one can see that Husserl's works are full of examples in which he has explained his method through using it for objects in nature. His examples of perception are of great significance in this regard. Phenomenological method is not restricted to the mind or spirit, in today's world it is being used in almost all fields of inquiry from the study of human psyche to the study of sound and environment and mobile phone designs. So, phenomenology in its application has really reached the place that Husserl conceived. Phenomenology has now become the method of almost all sciences, both natural and human. 


\section{Bibliography}

Aristotle, De Anima, tr. by J. A. Smith, Internet Classic Archive, Available Online: http://classics.mit.edu/Aristotle/soul.html

Aristotle, Categories, Book 1, tr. by: E.M Edghill, Internet Classic Archive: Available Online: $\underline{\text { http:/ / classics.mit.edu/ Aristotle/categories.html }}$

Aristotle, Metaphysics, tr. by: W. D. Ross, Internet Classic Archive: Available Online: http://classics.mit.edu/Aristotle/metaphysics.html

Aristotle, Topics, tr. by: W. A. Pickard-Cambridge, Internet Classic Archive: Available Online: http://classics.mit.edu/Aristotle/metaphysics.html

Husserl, E., Amsterdam Lectures, tr. by: R.E Palmer : available online: http://www.stanford.edu/dept/relstud/faculty/sheehan.bak/EHtrans/zamster.pdf

Husserl, E., Pure Phenomenology, its Method and its Field of Investigation, tr. by: Robert Welsh Jordan ; available online: http://lamar.colostate.edu/ rwjordan/WINAUGFRB.HTML

Witt, Ch.: Substance and Essence in Aristotle: An Interpretation of Metaphysics xii-ix; Cornell University Press, 1989. 


\section{E-LOGOS}

ELECTRONIC JOURNAL FOR PHILOSOPHY

Ročník/Year: 2014 (vychází průběžně/ published continuously)

Místo vydání/Place of edition: Praha

ISSN 1211-0442

Vydává/Publisher:

Vysoká škola ekonomická v Praze / University of Economics, Prague

nám. W. Churchilla 4

Czech Republic

13067 Praha 3

IČ: 61384399

Web: http://e-logos.vse.cz

Redakce a technické informace/Editorial staff and technical information:

Miroslav Vacura

vacuram@vse.cz

Redakční rada/Board of editors:

Ladislav Benyovszky (FHS UK Praha, Czech Republic)

Ivan Blecha (FF UP Olomouc, Czech Republic)

Martin Hemelík (VŠP Jihlava, Czech Republic)

Angelo Marocco (Pontifical Athenaeum Regina Apostolorum, Rome, Italy)

Jozef Kelemen (FPF SU Opava, Czech Republic)

Daniel Kroupa (ZU Plzeň, Czech Republic)

Vladimír Kvasnička (FIIT STU Bratislava, Slovak Republic)

Jaroslav Novotný (FHS UK Praha, Czech Republic)

Jakub Novotný (VŠP Jihlava, Czech Republic)

Ján Pavlík (editor-in-chief) (VŠE Praha, Czech Republic)

Karel Pstružina (VŠE Praha, Czech Republic)

Miroslav Vacura (executive editor) (VŠE Praha, Czech Republic) 